\title{
Stepwise Training for Reconstructive Microsurgery: The Journey to Becoming a Confident Microsurgeon in Singapore
}

\author{
Savitha Ramachandran ${ }^{1}$, Yee-Siang Ong ${ }^{2}$, Andrew YH Chin ${ }^{3}$, In-Chin Song ${ }^{4}$, Bryan Ogden ${ }^{4}$, \\ Bien-Keem Tan ${ }^{2}$ \\ ${ }^{1}$ Department of Plastic and Reconstructive Surgery, KK Women's and Children's Hospital, Singapore; ${ }^{2}$ Department of Plastic and Reconstruc- \\ tive Surgery, Singapore General Hospital, Singapore; ${ }^{3}$ Department of Hand Surgery, Singapore General Hospital, Singapore; ${ }^{4}$ Singhealth \\ Experimental Medicine Centre, Singapore
}

Microsurgery training in Singapore began in 1980 with the opening of the Experimental Surgical Unit. Since then, the unit has continued to grow and have held microsurgical training courses biannually. The road to becoming a full-fledged reconstructive surgeon requires the mastering of both microvascular as well as flap raising techniques and requires time, patience and good training facilities. In Singapore, over the past 2 decades, we have had the opportunity to develop good training facilities and to refine our surgical education programmes in reconstructive microsurgery. In this article, we share our experience with training in reconstructive microsurgery.

Keywords Microsurgery / Education / Reconstructive surgery
Correspondence:

Savitha Ramachandran

Department of Plastic and

Reconstructive Surgery, KK Women's and Children's Hospital, 100 Bukit

Timah Road, Singapore

Tel: +6581211485

Fax: +6563941154

E-mail: savitha.rama@gmail.com

No potential conflict of interest relevant to this article was reported.

\section{INTRODUCTION}

Microvascular surgery and flap raising are essential skills in the armamentarium of a reconstructive surgeon. Training to become an effective microsurgeon takes time and dedication. In Singapore, we direct training in a stepwise fashion, for trainees to establish competency in microvascular anastomosis and flap dissection. In this article, we share our experience with this approach to training and our insights into its challenges.

\section{MICROSURGERY TRAINING IN SIN- GAPORE: THE EARLYYEARS}

As microvascular surgery became a reality and revolutionized the field of plastic and reconstructive surgery in the 1970s, so did the demand for training in this sophisticated technique. In keeping with the exponential growth of this new subspecialty, the need for dedicated training facilities fueled the establishment of the Experimental Surgical Unit in the Singapore General Hospital in 1980. What began as a small lab with just $1 \mathrm{mi}-$ croscope, under the direction of Professor Robert Pho and dedicated laboratory technologist Mr. Robert Ng, has now grown into a facility with 20 fully equipped Leica microscopes (Fig. 1) and a fully staffed animal wet lab and cadaveric repository. In the last two decades, the basic microuresurgery course established with the help of Professor Colin Green from Northwick Park Hospital in the United Kingdom, is now well established, having just completed its 31st course in September 2012. This course,

Copyright () 2014 The Korean Society of Plastic and Reconstructive Surgeons

This is an Open Access article distributed under the terms of the Creative Commons Attribution Non-Commercial License (http://creativecommons.org/

licenses/by-nc/3.0/) which permits unrestricted non-commercial use, distribution, and reproduction in any medium, provided the original work is properly cited.

www.e-aps.org 


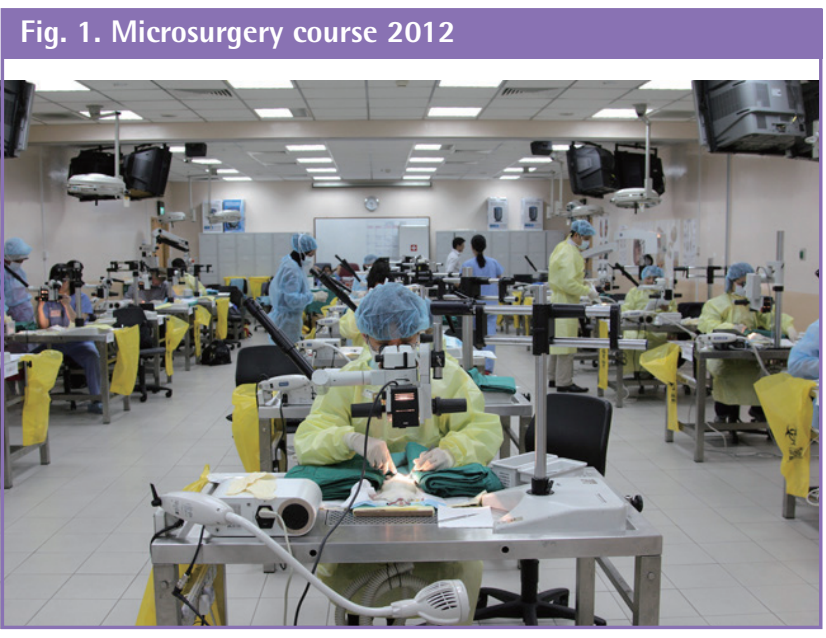

Fig. 2. Breakdown of participants by specialty in 2011 to 2012

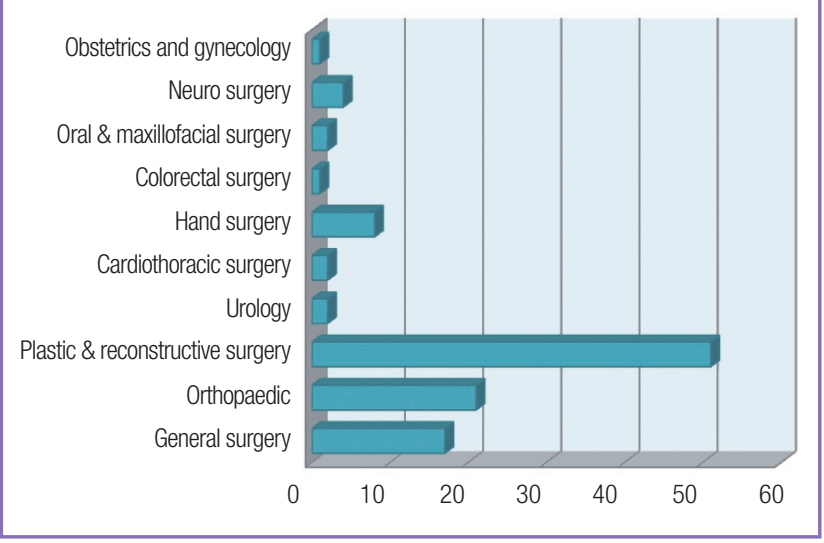

which is run biannually, is attended by both regional and international participants and is open to all surgical subspecialties, as illustrated in Fig. 2.

\section{PERFECTING ANASTOMOSIS}

The road to success begins with the 5-day basic course (www. microflapcourse.com), which is a mix of didactic lectures, Robert Acland videos, and hands-on training with table instructors. It starts with simple suturing on a latex card followed by the chicken aorta on day 1 . On day 2 , the tasks become progressively more challenging as participants are schooled in vessel dissection and preparation on a live rat, followed by microvascular anastomosis on the carotid vessels, and eventually the much smaller femoral vessels. On the final day of the course, they get a taste of the 'holy grail' of reconstructive microsurgery: the groin free flap transfer. Course materials include DVDs showing end-to-end and end-to-side (Fig. 3) [1] vessel anastomosis and nerve repair.
Fig. 3. End-to-side arterial anastomosis (From Tan BK, et al. J Plast Reconstr Aesthet Surg 2009;62:1519-23, with permission from Elsevier)

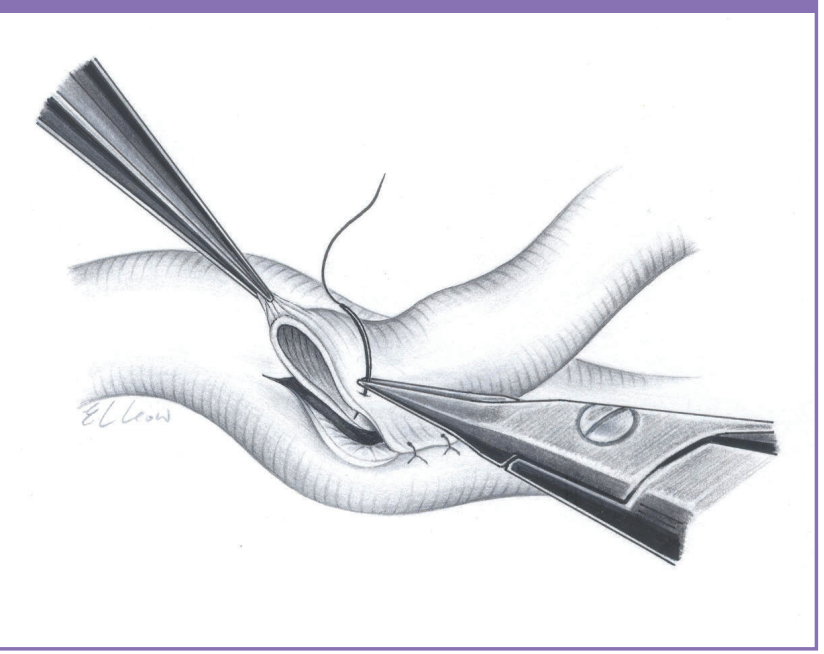

\section{SUCCESS IS A STATE OF MIND}

In addition to laying the foundation for good technique such as attention to posture, meticulous organization of the operative field, and accurate suture placement, we encourage trainees to develop an awareness of their mental state throughout the learning process. Similar to an archer aiming to shoot, adequate rest and a relaxed state of mind are cardinal. Therefore, participants are encouraged to proceed at their own pace, in a nurturing and pressure free environment and are advised not to proceed to the next exercise until they are comfortable with the current one.

Feedback on the course is generally good. In a recent editorial [2] published by a young resident, he shared the following:

"I remember vividly one of the faculty members saying at the very beginning of the course that more than anything, this would be a week about self-discovery. I was bemused at that time because surely I was here to learn how to do my anastomosis rather than self-reflection. Yet, with each passing day and each bit of amateurish microsurgical experience gained, I came to understand what he meant.

I adjusted and jousted for access to my vessels. Depending on the in vivo situation, I also tended to vary between operating either with my arms adducted close to my body or with my arms slightly abducted and my elbows resting on the operating table.

Finally, after correcting for all these individual quirks and nuances, one should be able to reach the level of relaxed concentration, a seemingly contradictory state of mind. And with this, on the final day of the course, I successfully performed my first free flap based on the superficial inferior epigastric artery albeit in a laboratory rat. This has only served to encourage me, more than ever, to pursue a career in plastic and reconstructive surgery." 


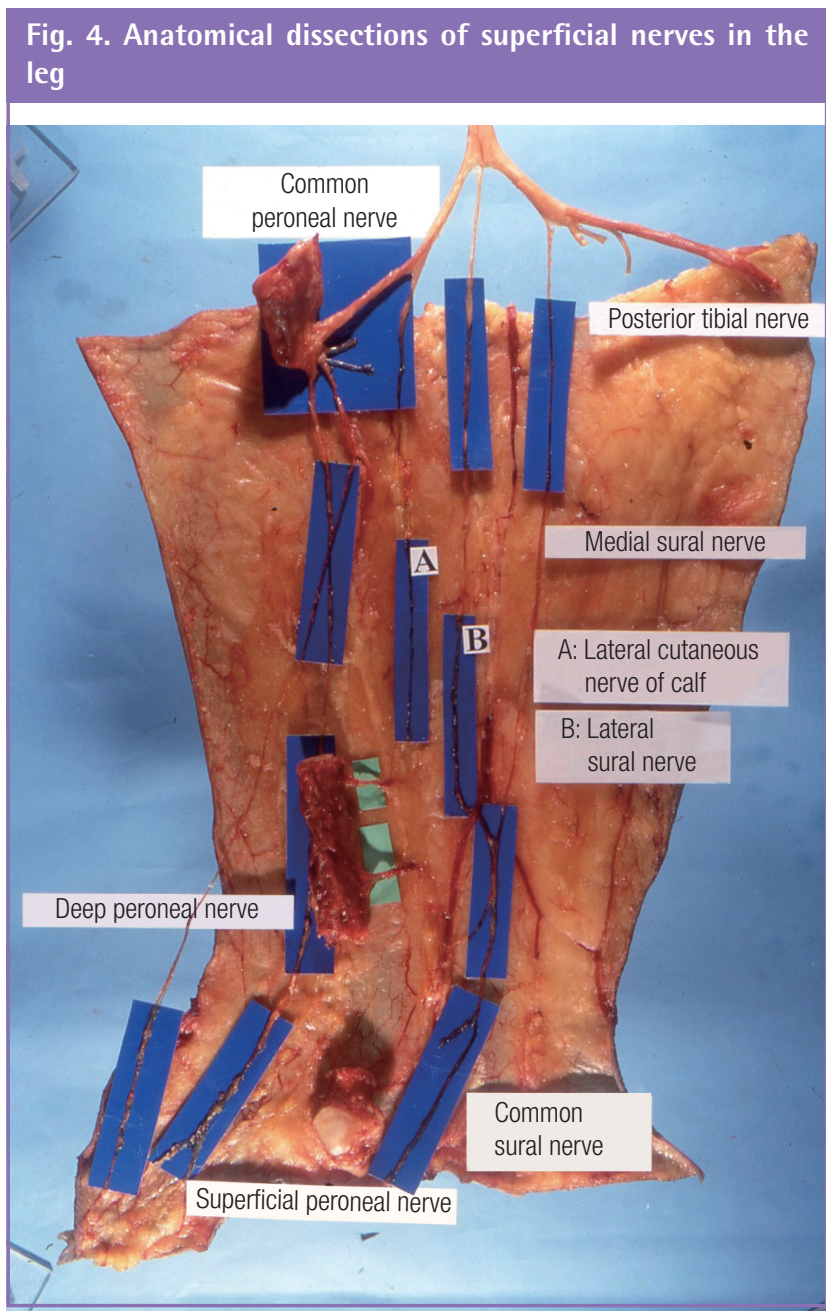

\section{PRACTICE MAKES PERFECT}

After stimulating their interest with the basic course, all trainees in plastic and hand surgery are encouraged to continue to hone their basic microsurgical skills by independent visits to the microsurgery lab to practice on a live rat model, embarking on research projects involving experimental microsurgery [1] and eventually participating in subsequent microsurgical courses as table instructors.

\section{BEYOND THE BASICS}

Competency in microanastomosis sets the platform for trainees to commence training in flap dissection. To familiarize themselves with dissection, tissue handling, and anatomy, everyone is encouraged to visit the lab to answer anatomical questions (Figs. $4,5)$ [3-8] and perform a 'dry-run' the day before surgery. More advanced trainees inject and prepare specimens and function as table instructors during the basic dissection courses.
Fig. 5. Dissection of the transverse cervical artery supplying the trapezius muscle flap

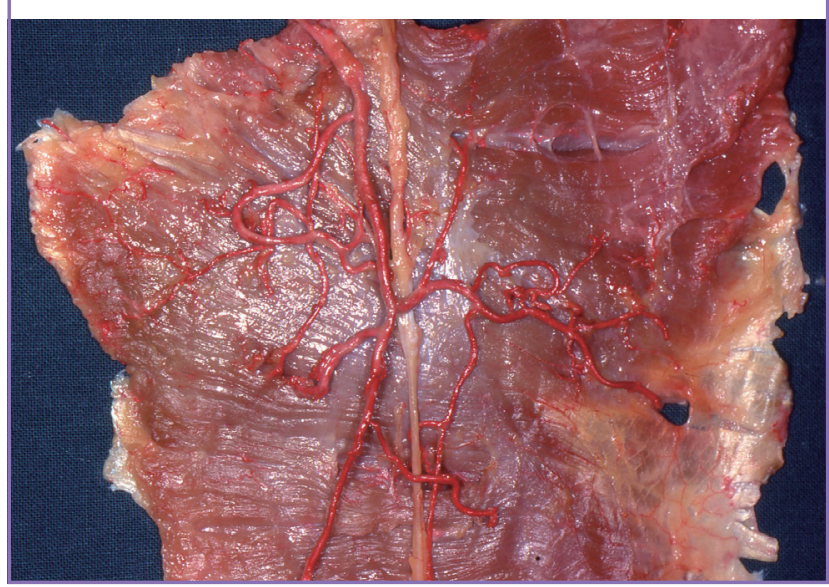

\section{CLINICAL APPRENTICESHIP}

Clinical apprenticeship is indispensable for trainees. All trainees begin their clinical training in microsurgery by assisting in microsurgical procedures in the operating theatre from the first year of training. After assisting for the first few months, they are able to perform an end-to-end anastomosis of the 3rd vein in a free flap. As they gain confidence, they move on to the $2 \mathrm{nd} / 1$ st vein and eventually arterial anastomosis.

\section{OUR INSIGHTS INTO MICROSURGI- CAL TRAINING}

The only journey is the one within.

-Rainer Maria Rilke

With the recent emphasis on objective assessment of microsurgical skill acquisition, there is pressure on all trainees and microsurgical educators to show proof of clinical competency. While there is no doubt about the importance of this, ensuring that training is done in an encouraging environment, in a stepwise fashion, and that allows trainees to reach competency at their own pace, is an important consideration. We continue to encourage our trainees to learn and hone their skills at their own pace in a nurturing environment. Teaching, acquiring knowledge, and practicing are imperative in the journey towards becoming a confident microsurgeon.

\section{REFERENCES}

1. Tan BK, Wong CH, Chew W, et al. Use of the slit arteriotomy for end-to-side arterial anastomosis in free-tissue transfers to the extremities. J Plast Reconstr Aesthet Surg 
2009;62:1519-23.

2. Ng ZY. 30th basic instructional course on microsurgery at the singapore general hospital: a week of self-discovery. Microsurgery 2012;32:659-62.

3. Wong CH, Ong YS, Chew KY, et al. The fibula osteoseptocutaneous flap incorporating the hemisoleus muscle for complex head and neck defects: anatomical study and clinical applications. Plast Reconstr Surg 2009;124:1956-64.

4. Wong CH, Tan BK. Perforator-sparing transposition flaps for lower limb defects: anatomic study and clinical application. Ann Plast Surg 2007;58:614-21.
5. Wong CH, Tan BK. Three-step approach to the harvest of the fibula osteoseptocutaneous flap. J Trauma 2010;69:45965.

6. Wong MZ, Wong CH, Tan BK, et al. Surgical anatomy of the medial sural artery perforator flap. J Reconstr Microsurg 2012;28:555-60.

7. Rasheed MZ, Tan BK, Tan KC. The extended lower trapezius flap for the reconstruction of shoulder tip defects. Ann Plast Surg 2009;63:184-7.

8. Tan BK, Wong CH, Chen HC. Anatomic variations in head and neck reconstruction. Semin Plast Surg 2010;24:155-70. 